\title{
Fibrin-Coated Collagen Fleece Seems to Prevent Sternal Instability after Cardiac Surgery: A Matched Pair Data Analysis
}

\author{
Peter Roth ${ }^{1}$ Jenna Stella ${ }^{1}$ Bernd Niemann ${ }^{1} \quad$ Philippe Grieshaber $^{1} \quad$ Rainer Roehrig $^{2}$ Andreas Böning ${ }^{1}$ \\ ${ }^{1}$ Department of Adult and Pediatric Cardiovascular Surgery, Giessen \\ University Hospital, Giessen, Germany \\ 2 Department of Medical Informatics, Carl von Ossietzky University \\ Oldenburg, Oldenburg, Germany \\ Address for correspondence Peter Roth, MD, Department of Adult \\ and Pediatric Cardiovascular Surgery, Giessen University Hospital, \\ Rudolf-Buchheimstr. 7, Giessen 35392, Germany \\ (e-mail: Peter.Roth@chiru.med.uni-giessen.de).
}

Thorac Cardiovasc Surg 2020;68:737-742.

\begin{abstract}
Keywords

- sternal instability

- fibrin-coated collagen fleece

- bone healing

- wound healing

Background To examine if fibrin-coated collagen fleece (Tachosil) interferes with bone and wound healing when it is used on the cut surface of the sternum after median sternotomy.

Methods A total of 25 patients with osteoporotic sternal disorders were treated with fibrincoated collagen fleece at the cut surface of the sternum after median sternotomy (therapy group). We compared the occurrence of impaired wound healing and sternal instability, reoperation rate, and 30-day mortality with a control group of 25 case-matched patients. After matching for age, gender, and risk factors for sternal instability (diabetes mellitus, osteoporosis, body mass index, nicotine consumption), both groups were comparable.

Results Sternal instability occurred in one (4\%) patient in the study group and in five (20\%) patients in the control group. Impaired wound healing occurred in one (4\%) patient in the therapy group and two (8\%) patients in the control group. Reoperation was necessary in four (16\%) patients in the therapy group and $6(24 \%)$ patients in the control group. The 30-day mortality occurred in six (24\%) patients in the therapy group and four (16\%) patients in the control group.

Conclusions The use of fibrin-coated collagen fleece on the cut surface of the sternum in patients with osteoporosis does not impair bone and wound healing. Furthermore, it seems to result in less sternal instability. A larger prospective study is necessary to verify the results of this explorative study.
\end{abstract}

\section{Introduction}

Sternal instability is a serious complication occurring in 0.25 to $7 \%$ of patients after cardiac surgery. ${ }^{1-3}$ In patients suffering from osteoporosis, the incidence of sternal instability rises up to $14 \%{ }^{4}$ Reoperation for sternal instability, prolonged hospital stay, and a mortality rate between 5 and 30\%, as well as rising costs, are the consequences. Osteoporosis, diabetes mellitus, use of bilateral mammary artery, and obesity are known risk factors for sternal instability and wound disorders. ${ }^{1,5-9}$

received

March 4, 2018

accepted after revision

June 26, 2018

published online

August 28, 2018
Fibrin-coated collagen fleece is routinely used to achieve hemostasis in all types of surgery. ${ }^{10-13}$ It can also be used to stop bleeding from cancellous bone. Nevertheless, so far, there are no data on the influence of fibrin-coated collagen fleece on bone and wound healing when used on the cut surface of the sternum after median sternotomy.

The aim of this study was to examine if fibrin-coated collagen fleece interferes with sternal stability and wound healing after median sternotomy. (c) 2018 Georg Thieme Verlag KG Stuttgart . New York
DOI https://doi.org/ 10.1055/s-0038-1667326. ISSN 0171-6425. 


\section{Materials and Methods}

All patients $(N=25)$ who were treated with fibrin-coated collagen fleece on the cut surface of the sternum between 2006 and 2011 were included in the study (therapy group). In all 25 patients, osteoporosis, defined as abnormal bone structure with thinning of the sternum and rarefication of cancellous bone, was found intraoperatively.

Baseline, intra-, and perioperative data of all 25 treated patients were compared retrospectively with 25 patients in a case-matched control group. The patients in the control group were known to suffer from osteoporosis preoperatively since diagnosis had been previously confirmed.

Noninfectious impaired wound healing (NIWH) was defined as a superficial wound dehiscence without signs of infection. Noninfectious sternal instability (NISI) was defined as sternal dehiscence with palpable crepitation without signs of infection. Superficial sternal wound infection (SSWI) was defined as warming, reddening, and superficial dehiscence of the sternal wound without sternal instability. Deep sternal wound infection (DSWI) was defined as wound secretion, deep dehiscence with sternal instability.

Surgery was performed in a standardized manner by the same surgeon (P. R.) in all patients of both groups.

Median sternotomy using a saber saw was performed after skin incision and transection of the subcutaneous tissue by diathermia. Different cardiac procedures were performed using cardiopulmonary bypass. At the end of surgery, sternal stabilization was achieved with eight single steel wires (stainless steel) in a standard manner. Before closure of the sternum by the implanted wires, a $9.6 \times 4.8 \mathrm{~cm}$ fibrin-coated collagen fleece (Tachosil, Takeda, Konstanz, Germany) was cut longitudinally in two halves $(9.6 \times 2.4 \mathrm{~cm})$, and each of the halves, with the fibrin-coated layer directing toward the cut surface, was pressed on one cut surface of both sides of the sternum for 2 minutes. Tachosil is waterproof and airtight and is completely resorbed within 13 weeks. Then, sternal steel wires were twisted with the two pieces of Tachosil between the two halves of the sternum. Vicryl single bottom sutures (Ethicon) were used for subcutaneous tissue closure. Skin closure was performed by intracutaneous running suture $(4 \times 0$ Ethilon, Ethicon).

\section{Data Analysis}

Patients were stepwise matched according to the following factors: gender, osteoporosis, diabetes mellitus, and nicotine consumption. In the second step, patients were matched for age ( \pm 6 years). In the third step, patients were matched for body mass index (BMI) $\left( \pm 3 \mathrm{~kg} / \mathrm{m}^{2}\right)$. In the last step, patients were matched for time frame of operation.

Statistical analysis was performed with SPSS (version 19, IBM Corp., Armonk, New York, United States). Average, median, minimum, and maximum, as well as percentiles and standard deviation were calculated for metric data. Categorical variables were compared using Fisher's exact test. Significance was assumed at $p \leq 0.05$. A trend to significance was supposed at $p<0.2$. Mann-Whitney $U$ test was used for the analysis of not normally distributed, unrelated parameters. Logistic regression analysis was used to quantify relationships between treatment modality (therapy group vs. control group) and adverse outcomes. Odds ratio were calculated.

The study protocol was approved by our university's Local Ethics Committee (vote 206/11).

\section{Results}

There were no differences between both groups regarding baseline characteristics with the exception of the predicted risk of mortality and priority of surgery (-Table 1). Especially, the known risk factors for sternal instability (diabetes

Table 1 Baseline characteristics

\begin{tabular}{|c|c|c|c|}
\hline & $\begin{array}{l}\text { Therapy } \\
\text { group } \\
(N=25)\end{array}$ & $\begin{array}{l}\text { Control } \\
\text { group } \\
(N=25)\end{array}$ & $p$-Value \\
\hline Age (mean) & 74 & 71 & 0.586 \\
\hline Male & $3(12 \%)$ & $3(12 \%)$ & 1.000 \\
\hline Female & $22(88 \%)$ & $22(88 \%)$ & 1.000 \\
\hline IDDM & $11(44 \%)$ & $12(48 \%)$ & 1.000 \\
\hline SSRI & $2(8 \%)$ & 0 & 0.490 \\
\hline $\begin{array}{l}\text { Height }(\mathrm{cm}) \\
\text { (mean) }\end{array}$ & $164 \pm 8$ & $161 \pm 9$ & 0.321 \\
\hline $\begin{array}{l}\text { Weight }(\mathrm{kg}) \\
\text { (median) }\end{array}$ & 70 & 70 & 0.662 \\
\hline $\begin{array}{l}\text { BMI }\left(\mathrm{kg} / \mathrm{m}^{2}\right) \\
(\text { median) }\end{array}$ & 27 & 26 & 1.000 \\
\hline Nicotine & $6(24 \%)$ & $5(20 \%)$ & 1.000 \\
\hline Osteoporosis & 25 (100\%) & 25 (100\%) & 1.000 \\
\hline BIMA & 0 & $2(8 \%)$ & 0.490 \\
\hline $\begin{array}{l}\text { Anticoagulation } \\
\text { therapy }\end{array}$ & $10(40 \%)$ & $9(36 \%)$ & 1.000 \\
\hline $\begin{array}{l}\text { Peripheral } \\
\text { vascular disease }\end{array}$ & $1(4 \%)$ & $4(16 \%)$ & 0.349 \\
\hline $\begin{array}{l}\text { Cortisol } \\
\text { medication }\end{array}$ & $0(0 \%)$ & $2(8 \%)$ & 0.490 \\
\hline ASA 3 & 17 (68\%) & $22(88 \%)$ & \\
\hline ASA 4 & 7 (28\%) & $2(8 \%)$ & 0.181 \\
\hline ASA 5 & $1(4 \%)$ & $1(4 \%)$ & \\
\hline Elective & $11(44 \%)$ & $22(88 \%)$ & \\
\hline Urgent & $6(24 \%)$ & $1(4 \%)$ & 0.004 \\
\hline Emergent & $8(32 \%)$ & $2(8 \%)$ & \\
\hline $\begin{array}{l}\text { EuroSCORE I } \\
\text { (points) }\end{array}$ & $10 \pm 3$ & $8 \pm 4$ & 0.034 \\
\hline
\end{tabular}

Abbreviations: ASA, American Society of Anaesthesiologists classification; BIMA, bilateral internal thoracic arteries; BMI, body mass index; EuroSCORE, European system for cardiac operative risk evaluation; IDDM, insulin-dependent diabetes mellitus; SSRI, selective serotonin reuptake inhibitor.

Note: There were no differences between groups in baseline characteristics, except urgency of operations and predicted mortality (EuroSCORE I). 
Table 2 Surgical procedures and perioperative data

\begin{tabular}{|l|l|l|l|}
\hline Operation & $\begin{array}{l}\text { Therapy } \\
\text { group } \\
(N=25)\end{array}$ & $\begin{array}{l}\text { Control } \\
\text { group } \\
(N=25)\end{array}$ & $p$-Value \\
\hline CABG & 11 & 11 & \\
\hline AVR & 5 & 10 & \\
\hline MVR & 4 & 1 & \\
\hline TVR & 0 & 2 & \\
\hline Heart tumor & 1 & 0 & 0.541 \\
\hline Aortic surgery & 4 & 1 & 0.719 \\
\hline $\begin{array}{l}\text { ECC (minutes) } \\
\text { (median) }\end{array}$ & 103 & 103 & 0.611 \\
\hline $\begin{array}{l}\text { Operation time } \\
\text { (minutes) } \\
\text { (median) }\end{array}$ & 222 & 205 & 0.240 \\
\hline $\begin{array}{l}\text { LOS (days) } \\
\text { (median) }\end{array}$ & 16 & 16 & 5 \\
\hline LOS ICU (days) & 7 & 5 & $230.5 \pm 123.3$ \\
\hline $\begin{array}{l}\text { CRP max } \\
\text { (mg/L) }\end{array}$ & $193.6 \pm 76.2$ & 205 & \\
\hline
\end{tabular}

Abbreviations: AVR, aortic valve replacement; $C A B G$, coronary artery bypass grafting; CRP, C-reactive protein; ECC, extracorporeal circulation; LOS, length of stay; LOS ICU, length of stay intensive care unit; MVR, mitral valve reconstruction; TVR, tricuspid valve reconstruction.

mellitus, BMI, osteoporosis, nicotine consumption, use of bilateral internal mammary artery (BIMA) grafts, and cortisol therapy) were not different. In the therapy group, there were more urgent ( 24 vs. $4 \%$ ) and emergent (32 vs. $8 \%$ ) patients than in the control group $(p=0.004)$.

Surgical procedures and perioperative data are shown in - Table 2. In the therapy group, there were less aortic valve replacements (AVRs) and more mitral valve replacements and aortic operations. Operation time (OP), length of stay (LOS), and length of stay in intensive care unit were similar in both groups.

Sternal instability occurred in $6(12 \%)$ of the 50 patients ( - Table 3). The mean time interval from surgery until the occurrence of sternal instability was 15 days (range: 7-21 days; median: 18). Five of those six patients were reoperated on, and one of the patients with sternal instability died before reoperation. Of the six patients with sternal instability, two had a DSWI (one in each group) and four had an NISI (all in the control group).

There were less sternal instabilities in the therapy group $(N=1 ; 4 \%)$ than in the control group $(N=5 ; 20 \% ; p=0.19)$. The odds ratio for sternal instability was 0.17 (95\% confidence interval [CI]: 0.018-1.5) in the therapy group (- Fig. 1).

We observed $10(20 \%)$ cases of impaired wound healing. There were more cases in the control group $(N=6 ; 24 \%)$ than in the therapy group $(N=4 ; 16 \% ; p=0.73)$.

From those 10 patients, 6 patients had NIWH and 4 had wound infections: 2 SSWI (one in each group) and 2 DSWI (one in each group). These four patients needed wound revision ( - Table 4$)$. The other six patients were treated conservatively. The odds ratio for NIWH in the therapy group compared with the control group was 0.46 (95\% CI: 0.00762.8 ) and that for infectious wound healing impairment was 1 (95\% CI: 0.36-2.8) (- Fig. 1). In addition, the mean C-reactive protein level was lower in the therapy group than in the control group (not significant), showing that there is no increased inflammatory reaction caused by the use of fibrin-coated collagen fleece ( $\mathbf{-}$ Table 2 ).

Of out 50 patients, 10 had a reoperation (20\%): 4 patients were in the therapy group (16\%) and 6 in the control group (24\%). The difference was not statistically significant $(p=0.73)$.

The reasons for reoperations were sternal instability in five (50\%; three NISI and two DSWI) patients, bleeding in two (20\%) patients, SSWI in two (20\%) patients, and pericardial effusion in one (10\%) patient. Data of the patients who were reoperated on are shown in - Table 4.

The odds ratio for reoperation in the therapy group compared with the control group was $0.6(95 \% \mathrm{Cl}$ : $0.15-$ 2.47) (-Fig. 1).

The predicted mortality calculated by the European system for cardiac operative risk evaluation (EuroSCORE) I was higher in the therapy group ( $10 \pm 3$ vs. $8 \pm 4$ points; $p=0.034 ; 22.5$ vs. $15.4 \%)$. Total 30 -day mortality in our study was $12 \%(16 \%$ $[N=4]$ in the therapy group and $8 \%[N=2]$ in the control group), which was lower than the predicted mortality but reasonable for the high-risk collective ( $\mathbf{- T a b l e ~} \mathbf{5}$ ). Only one

Table 3 Data of all patients suffering from sternal instability after the index procedure

\begin{tabular}{|l|l|l|l|l|l|l|l|l|l|l|}
\hline Patient & Group & Age & Sex & Procedure & Urgency & $\begin{array}{l}\text { Time interval to } \\
\text { occurrence (days) }\end{array}$ & $\begin{array}{l}\text { LOS } \\
\text { ICU }\end{array}$ & Mortality & BMI & DM \\
\hline 1 & Therapy & 67 & F & MVR & Urgent & 21 & 34 & No & 33.5 & Yes \\
\hline 2 & Control & 52 & M & CABG & Elective & 19 & 9 & No & 34.7 & No \\
\hline 3 & Control & 59 & F & AVR & Elective & 10 & 11 & Yes & 23.1 & No \\
\hline 4 & Control & 71 & F & AVR & Emergent & 18 & 25 & No & 27 & Yes \\
\hline 5 & Control & 77 & F & CABG & Urgent & 7 & 13 & No & 27.5 & No \\
\hline 6 & Control & 82 & F & CABG & Elective & 19 & 27 & No & 19.5 & Yes \\
\hline
\end{tabular}

Abbreviations: AVR, aortic valve replacement; BMI, body mass index; CABG, coronary artery bypass grafting; DM, diabetes mellitus; LOS ICU, length of stay intensive care unit; MVR, mitral valve reconstruction.

Note: One patient in the therapy group and five in the control group had sternal instability. 


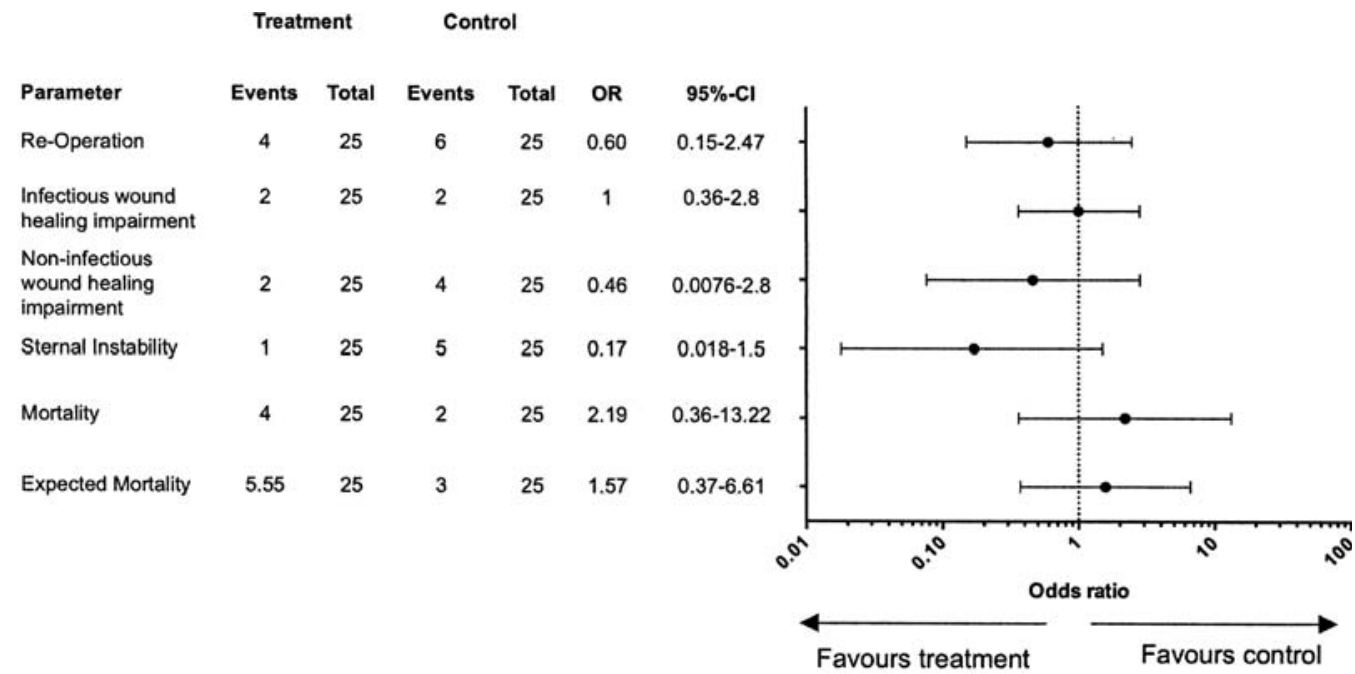

Fig. 1 Odds ratio.

patient who died suffered from an NISI. This patient was in the control group. The patient was a 59-year-old woman, who died after elective AVR at day 11 due to septic multiorgan failure. Preoperative EuroSCORE was 3.

The other five patients died because of cardiogenic shock (7th day), septic shock (25th day), lung embolism (2nd day), and pneumonia (23rd and 28th day). The EuroSCORE of the five patients has been higher than the average (between 11 and 13 points). None of these five patients had sternal instability (-Table 5). The odds ratio for mortality in the therapy group was 2.19 (95\% CI: $0.36-13.22$ ). The odds ratio for the predicted mortality in the therapy group was 1.57 (95\% CI: 0.37-6.61).

\section{Discussion}

Median sternotomy is the standard approach in cardiac surgery. Bleeding from the cut surface of the sternum is difficult to treat and might be a reason for reoperation. Sutures and diathermia are not really suitable to stop such bleedings. The most common treatment is the use of bone wax, which itself might compromise the bone healing. ${ }^{14-16}$ Fibrin-coated collagen fleece is a treatment option for the management of bone bleedings. There is no published experience with fibrin-coated collagen fleece used on the cut surface of bones so far.

It is well known that foreign material in surgical wounds, such as sutures, vascular clips, vascular prostheses, pacemakers and others implants, can lead to impaired wound healing and wound infections. ${ }^{17,18}$ Even though fibrincoated collagen fleece, used to achieve hemostasis or prevent adhesions, is completely resorbed, it is a foreign material in a surgical wound and might influence wound healing and cause wound infection. We hypothesized, therefore, that the use of fibrin-coated collagen fleece impairs sternal stability, wound healing, and the occurrence of wound

Table 4 Reoperation

\begin{tabular}{|c|c|c|c|c|c|c|}
\hline Patient & Group & $\begin{array}{l}\text { Day of first } \\
\text { reoperation }\end{array}$ & $\begin{array}{l}\text { Reason for } \\
\text { reoperation }\end{array}$ & Procedure & $\begin{array}{l}\text { No. of } \\
\text { reoperation }\end{array}$ & LOS ICU \\
\hline 1 & Therapy & 14 & Bleeding & Hematoma evacuation & 1 & 86 \\
\hline 2 & Therapy & 21 & DSWI & VAC and omentum plasty & 4 & 34 \\
\hline 3 & Therapy & 0 & Bleeding & Hematoma evacuation & 1 & 7 \\
\hline 4 & Therapy & 8 & SSWI & Wound debridement & 1 & 37 \\
\hline 5 & Control & 19 & $\mathrm{NISI}$ & Sternal restabilization & 1 & 9 \\
\hline 6 & Control & 25 & Pericardial effusion & Pericardial fenestration & 1 & 10 \\
\hline 7 & Control & 6 & SSWI & Wound debridement & 1 & 2 \\
\hline 8 & Control & 7 & $\mathrm{NISI}$ & Sternal restabilization & 1 & 13 \\
\hline 9 & Control & 19 & DSWI & VAC and pectoralis plasty & 9 & 27 \\
\hline 10 & Control & 18 & $\mathrm{NISI}$ & Sternal restabilization & 1 & 25 \\
\hline
\end{tabular}

Abbreviations: DSWI, deep sternal wound infection; LOS ICU, length of stay intensive care unit; NISI, noninfectious sternal instability; SSWI, superficial sternal wound infection; VAC, vacuum-assisted closure.

Note: Four patients in the therapy group and six in the control group needed reoperation. 
Table 5 Risk factors and reasons for death

\begin{tabular}{|l|l|l|l|l|l|l|l|l|l|}
\hline Patient & Group & Age & Sex & Procedure & $\begin{array}{l}\text { Euro } \\
\text { SCORE } \\
\text { (points) }\end{array}$ & Reoperation & $\begin{array}{l}\text { Sternal } \\
\text { instability }\end{array}$ & $\begin{array}{l}\text { Day of } \\
\text { mortality }\end{array}$ & Cause of mortality \\
\hline 1 & Therapy & 41 & M & CABG & 12 & No & No & 7 & Cardiogenic shock \\
\hline 2 & Therapy & 71 & F & CABG & 11 & No & No & 25 & Septic shock \\
\hline 3 & Therapy & 55 & F & $\begin{array}{l}\text { Pulmonary } \\
\text { embolectomy }\end{array}$ & 13 & No & No & 2 & Right heart failure \\
\hline 4 & Therapy & 74 & F & CABG & 12 & No & No & 28 & Pneumonia \\
\hline 5 & Control & 59 & F & AVR & 3 & No & Yes & 11 & $\begin{array}{l}\text { Septic multiorgan } \\
\text { failure }\end{array}$ \\
\hline 6 & Control & 83 & F & CABG & 13 & No & No & 23 & Pneumonia \\
\hline
\end{tabular}

Abbreviations: AVR, aortic valve replacement; CABG, coronary bypass grafting; EuroSCORE, European system for cardiac operative risk evaluation. Note: Four patients in the therapy group and two in the control group died.

infections after median sternotomy in cardiac surgery when used on the cut surface of the sternum. To verify this hypothesis, we analyzed the data of 25 consecutive patients with fibrin-coated collagen fleece on the cut surface of the sternum after median sternotomy.

Sternal instability after median sternotomy is a serious complication after cardiac surgery, containing the risk of sternal infection and mediastinitis, which is a major cause of morbidity and mortality. ${ }^{19}$ In patients above 65 years of age suffering from osteoporosis, sternal instability appears in up to $14 \%$ after median sternotomy. For this reason, our patients represent a high-risk collective for sternal instability and wound infections, and our results $(n=6 ; 12 \%)$ are in accordance with the literature. ${ }^{20}$

Surprisingly, our data show that the use of fibrin-coated collagen fleece on the cut surface of the sternum does not impair sternum stability after median sternotomy. There was only one sternum instability in the therapy group but five in the control group. Even though there is no statistical difference in this end point, there is a trend toward worse results in the control group concerning sternum instability $(p=0.19)$. This means that the use of fibrin-coated collagen fleece could probably even decrease the risk of sternal instability in this high-risk group.

Noninfectious wound disorders also occurred in more cases in the control group than in the therapy group (four vs. two), but sternal wound infections were equal in both groups (one SSWI and one DSWI each). These results demonstrate that the use of fibrin-coated collagen fleece on the cut surface of the sternum did not impair wound healing in terms of infection.

No mortality has been caused by sternal instability or wound healing in either group. Only one patient from the control group who died had noninfectious sternum instability 10 days after surgery. Unfortunately, she expired at day 11 after surgery due to septic multiorgan failure before the revision of the sternum could be performed (-Table 3).

The overall mortality in our high-risk therapy group was $12 \%$, which is high in comparison with a normal patient collective but lower than the predicted mortality for our patient group (19\%, EuroSCORE I).

The higher mortality rate in the therapy group compared with the control group (-Table $\mathbf{3}$ ) is mainly explained by the significantly higher predicted risk profile of this group arising from EuroSCORE I (22.5 vs. $15.4 \%$; $p=0.026)$ and the differences in the baseline characteristics (more urgent and emergent procedures in the therapy group). The actual mortality in both groups was lower than predicted (12 and $8 \%$ ).

The all-cause reoperation rate was also high $(20 \% ; 10 / 50$ patients), which is mainly explained by the risk profile of the patients and the type of surgery. Of the patients, $88 \%$ were female, all suffered from osteoporosis, and $48 \%$ had insulindependent diabetes mellitus. This is the reason why our collective had a high risk of sternal instability and wound infections. Only $44 \%$ of the procedures were coronary artery bypass grafting and $56 \%$ of the operations were valve or aortic surgery. Consequently, the vast majority ( $7 / 10)$ of reoperations had to be performed because of sternal instability (4/10) and wound disorders (3/10). The remaining reoperations were rethoracotomies for bleeding $(2 / 10)$ and for pericardial effusion $(1 / 10)(-$ Table 4$)$.

Of these reoperations, there were more which occurred in the control group compared to the therapy group. From the six reoperations in the control group, three had to be performed due to sternal instability. From the four reoperations in the therapy group, only one was due to sternal instability. Of course, the difference was statistically not significant $(p=0.73$ ) due to the low patient numbers. Two further patients of each group were reoperated due to wound healing impairment.

Similar to the sternal instability data, the results show that the use of fibrin-coated collagen fleece on the cut surface of the sternum does not increase the risk of reoperation.

Our results lead to a hypothesis change in such a way that the use of fibrin-coated collagen fleece on the cutting surface of the sternum prevents sternal instability and impaired wound healing after median sternotomy in a high-risk population. To confirm this hypothesis, a larger prospective 
randomized follow-up study is in preparation. The study presented here will be used for calculation of the required number of cases in the study. Besides the benefits for the patients, the economic aspect is also of great interest. The question whether the costs of the fibrin-coated collagen fleece balance the expenses saved on reoperations has to be analyzed. Furthermore, the patient collective who benefits from the treatment with fibrin-coated collagen fleece has to be defined.

\section{Conclusion}

Our hypothesis that fibrin-coated collagen fleece impairs sternal stability, wound healing, and the occurrence of wound infections after median sternotomy is not supported by our data. Furthermore, our data show that fibrin-coated collagen fleece could probably even prevent sternal instability and reoperations due to sternal complications. In summary, we could show that fibrin-coated collagen fleece can be used on the cut surface of the sternum for controlling bone bleeding without increasing wound disorders, sternal instability, and mortality. A larger prospective study is necessary to investigate this assumption.

\section{Limitations}

Even though both groups were accurately matched, the retrospective, nonrandomized character of the study and the small number of patients are relevant limitations. Due to the retrospective character of the study, there were no bone density measurements available to objectify osteoporosis. Osteoporosis was taken as given, when thinning of sternum and rarefication of cancellous bone was seen intra-operatively in the therapy group and when the diagnosis of osteoporosis was known preoperatively in the control group. In addition, bone healing was not confirmed by computed tomography (CT) scan postoperatively.

There might be a selection bias because the decision regarding the use of fibrin-coated collagen fleece has been made by the surgeon during the operation. However, this bias would have led to inclusion of patients at an even higher risk in the therapy group and more wound healing impairment would have been expected in those patients treated with collagen fleece. Furthermore, as only one surgeon performed all operations, consistency in this decisionmaking can be assumed.

Conflict of Interest

None declared.

\section{Acknowledgment}

The authors would like to thank Raphael W. Majeed for the assistance in data analysis.

\section{References}

1 Baskett RJ, MacDougall CE, Ross DB. Is mediastinitis a preventable complication? A 10-year review. Ann Thorac Surg 1999;67(02): 462-465

2 Furnary AP, Zerr KJ, Grunkemeier GL, Starr A. Continuous intravenous insulin infusion reduces the incidence of deep sternal wound infection in diabetic patients after cardiac surgical procedures. Ann Thorac Surg 1999;67(02):352-360, discussion 360-362

3 Ridderstolpe L, Gill H, Granfeldt H, Ahlfeldt H, Rutberg H. Superficial and deep sternal wound complications: incidence, risk factors and mortality. Eur J Cardiothorac Surg 2001;20(06): 1168-1175

4 Jenny NS, Arnold AM, Kuller LH, Tracy RP, Psaty BM. Serum amyloid $\mathrm{P}$ and cardiovascular disease in older men and women: results from the Cardiovascular Health Study. Arterioscler Thromb Vasc Biol 2007;27(02):352-358

5 Abboud CS, Wey SB, Baltar VT. Risk factors for mediastinitis after cardiac surgery. Ann Thorac Surg 2004;77(02):676-683

6 El Oakley RM, Wright JE. Postoperative mediastinitis: classification and management. Ann Thorac Surg 1996;61(03):1030-1036

7 Loop FD, Lytle BW, Cosgrove DM, et al. J. Maxwell Chamberlain memorial paper. Sternal wound complications after isolated coronary artery bypass grafting: early and late mortality, morbidity, and cost of care. Ann Thorac Surg 1990;49(02):179-186, discussion 186-187

8 Vallely MP, Edelman JJB, Wilson MK. Bilateral internal mammary arteries: evidence and technical considerations. Ann Cardiothorac Surg 2013;2(04):570-577

9 Bitkover CY, Gårdlund B. Mediastinitis after cardiovascular operations: a case-control study of risk factors. Ann Thorac Surg 1998; 65(01):36-40

10 Bajardi G, Pecoraro F, Mirabella D. Efficacy of TachoSil patches in controlling Dacron suture-hole bleeding after abdominal aortic aneurysm open repair. J Cardiothorac Surg 2009;4:60

11 Rousou JA. Use of fibrin sealants in cardiovascular surgery: a systematic review. J Card Surg 2013;28(03):238-247

12 Agus GB, Bono AV, Mira E, et al. Hemostatic efficacy and safety of TachoComb in surgery. Ready to use and rapid hemostatic agent. Int Surg 1996;81(03):316-319

13 Maisano F, Kjaergård HK, Bauernschmitt R, et al. TachoSil surgical patch versus conventional haemostatic fleece material for control of bleeding in cardiovascular surgery: a randomised controlled trial. Eur J Cardiothorac Surg 2009;36(04):708-714

14 Bhatti F, Dunning J. Does liberal use of bone wax increase the risk of mediastinitis? Interact Cardiovasc Thorac Surg 2003;2(04):410-412

15 Mair H, Kaczmarek I, Oberhoffer M, Groetzner J, Daebritz S, Reichert B. Surgical Nu-Knit hemostat for bleeding control of fragile sternum. J Thorac Cardiovasc Surg 2005;130(02): 605-606

16 Vestergaard RF, Jensen H, Vind-Kezunovic S, Jakobsen T, Søballe K, Hasenkam JM. Bone healing after median sternotomy: a comparison of two hemostatic devices. J Cardiothorac Surg 2010;5(01): 117

17 Lammers RL. Soft tissue foreign bodies. Ann Emerg Med 1988;17 (12):1336-1347

18 Sung KY, Lee SY. A chronic, nonhealing wound of the finger caused by polypropylene suture material. Wounds 2015;27(07):E16-E19

19 Satta J, Lahtinen J, Räisänen L, Salmela E, Juvonen T. Options for the management of poststernotomy mediastinitis. Scand Cardiovasc J 1998;32(01):29-32

20 Kirbas A, Celik S, Gurer O, Yildiz Y, Isik O. Sternal wrapping for the prevention of sternal morbidity in elderly osteoporotic patients undergoing median sternotomy. Tex Heart Inst J 2011;38(02): 132-136 